\title{
Mindfulness in organizations (part 2): a practitioners' guide to applying mindfulness based approaches in leadership development, workplace wellbeing and coaching
}

Article

Accepted Version

Passmore, J. (2019) Mindfulness in organizations (part 2): a practitioners' guide to applying mindfulness based approaches in leadership development, workplace wellbeing and coaching. Industrial and Commercial Training, 51 (3). pp. 165-173. ISSN 0019-7858 doi: https://doi.org/10.1108/ICT-07-2018-0064 Available at https://centaur.reading.ac.uk/81946/

It is advisable to refer to the publisher's version if you intend to cite from the work. See Guidance on citing.

To link to this article DOI: http://dx.doi.org/10.1108/ICT-07-2018-0064

Publisher: Emerald

All outputs in CentAUR are protected by Intellectual Property Rights law, including copyright law. Copyright and IPR is retained by the creators or other copyright holders. Terms and conditions for use of this material are defined in the End User Agreement. 


\section{www.reading.ac.uk/centaur}

\section{CentAUR}

Central Archive at the University of Reading

Reading's research outputs online 


\title{
Mindfulness in organizations (Part 2): A practitioners' guide to applying mindfulness based approaches in leadership development, workplace wellbeing and coaching
}

\begin{abstract}
Purpose: This paper explores the application of mindfulness in organizational development to provide a useful guide for practitioners in their work as managers, consultants and coaches.

Approach: The paper offers practical applications of mindfulness in organizations, specifically its use in leadership development, organizational wellbeing and coaching.

Findings: The paper notes a variety of ways in which mindfulness can be applied. While it recognizes that the research into the application of mindfulness at work is under developed, it suggests that through applied organizational research can enhance our understanding.

Practical implications: The paper provides insights drawn from practice that can be applied by HR practitioners or consultants addressing modern organizational challenges from workplace stress to developing leaders with greater situational awareness and empathy.
\end{abstract}

Originality: The paper is distinctive in providing a strong practitioners focus and from shifting the focus from the individual towards considering organizational benefits that may be obtained from workplace mindfulness programmes.

Key words: Mindfulness at work, leadership development, wisdom, mindfulness coaching, wellbeing at work.

Paper type: Practice paper

Passmore, J. (2019). Mindfulness in organizations (Part 2): A practitioners' guide to applying mindfulness based approaches in leadership development, workplace wellbeing and coaching. Industrial and Commercial Training. DOI: 10.1108/ICT-072018-0064 


\section{Introduction}

Organizations today are confronted by challenges brought by globalization, growing cultural differences in the workforce, enhanced connectivity and a constant drive for efficiency. In the last paper (Passmore, 2019) we discussed these forces for change and the potential for mindfulness as a tool to help both employees and organizations to be better able to manage the challenges of 'the modern age'.

We noted in the previous paper that mindfulness has exploded in popularity, with the development of multiple health-based programmes, leading to greater coverage in both academic journals and life style magazines. In response organizations too have looked to mindfulness as a possible tool to enhance wellbeing and performance. Companies as diverse as Google and the US Army have looked to mindfulness to support employee development. There has also been a similar growth in specialist providers from organizations like the Potential Project and the Mindfulness Coaching School.

While the evidence for mindfulness as a health intervention is compelling, there is less evidence supporting the application of mindfulness as a workplace intervention. We previously argued that caution was needed before making excessive claims in favour of workplace mindfulness. We suggested that more research was needed to deepen and broaden the evidence base, assessing organizational benefits at a quantitative level as well as a qualitative level. A movement from exploring the felt experience of participants to measuring the financial benefits of mindfulness based programmes such as their potential impact on absenteeism or enhanced individual performance, and using methods such as randomised control trails, larger sample sizes and across multiple sectors.

In this paper we aim to explore how mindfulness interventions could be developed as an element within common organizational interventions such as leadership development, workplace wellbeing programmes and coaching and secondly, responding to the call for more research, we suggest how practitioners could evaluate these interventions.

\section{What is mindfulness?}

The term mindfulness is derived from a translation of the term 'Sati'. Sati combines aspects of 'awareness', 'attention' and 'remembering', which are combined with 'non-judgement', 'acceptance', 'kindness' and 'friendliness' to oneself and others.

A number of writers have offered definitions of mindfulness over the two thousand five hundred years of its history. Chaskalson suggests it is 'the quality of awareness that comes from paying attention to yourself, others and the world around you' (Chaskalson, 2014, p6). In contrast, Kabat-Zinn suggests it is a way of paying 
attention on purpose in the present moment and non-judgementally (Kabat-Zinn, 1991).

\section{Mindfulness in practice}

The previous paper (Passmore, 2019) reviewed the research literature and explored mindfulness as an intervention in both health and organizational settings. In the following section this paper we explore the application of mindfulness in leadership development, coaching and decision-making.

\section{Leadership development}

Leadership development programmes have become ubiquitous over the past two decades. Organizations now have programmes and talent management pipelines aimed at every strata of their organizations. These programmes have tended to focus on exploring models of leadership, applying concepts such as emotional intelligence or resilience and helping individuals develop the strategic and systemic awareness needed in senior roles. One factor that has been neglected, but is becoming more prominent, is the role of wisdom, or leadership maturity.

Wisdom is valued by almost all societies, but we particularly notice its presence or absence amongst leaders, whether they are the US President or a team supervisor. Most people appreciate that wisdom is something different to intelligence, but find it hard to precisely define the concept. A commonly held view is that wisdom is acquired with age and mostly developed through self-reflection. For most casual observers it is often expressed through a calm and confident manner. The lack of clarity about what is wisdom and how it can be acquired, measured or developed has meant the concept has tended to remain the preserve of philosophers, who have debated the construct, leaving organizational researchers to direct their attention to other attributes.

In the past two decade, this has started to change. Early attempts, such as the work of Baltes and Meeks, explored the concept and suggested that wisdom could be analyzed and categorized like any other psychological construct. Baltes suggested that wisdom consists of five factors that we can measure and more importantly, develop (Baltes \& Stuadinger, 2000). Meeks, created a framework containing six components (Meeks, Dilip \& Jeste, 2009), adding to Baltes original work the idea of reflection. That wisdom emerged from reflective practice. A review of these constructs suggests both models' have significant commonality (see Table 1).

Table 1: Comparison of Baltes and Meeks models of wisdom

\begin{tabular}{|l|l|}
\hline Baltes - Five Factors & Meeks, Dilip \& Jeste - Six Factors \\
\hline Factual knowledge & Prosocial behaviours \\
\hline Procedural knowledge & Social decision-making \\
\hline
\end{tabular}

Passmore, J. (2019). Mindfulness in organizations (Part 2): A practitioners' guide to applying mindfulness based approaches in leadership development, workplace wellbeing and coaching. Industrial and Commercial Training. DOI: 10.1108/ICT-072018-0064 


\begin{tabular}{|l|l|}
\hline Lifespan contextualism & Emotional homeostasis \\
\hline Value relativism & Value relativism \\
\hline $\begin{array}{l}\text { Awareness and management } \\
\text { of uncertainty }\end{array}$ & Managing uncertainty \\
\hline & Reflection \\
\hline
\end{tabular}

In our own practice working with clients, what struck us was the overlap between mindful meditation and wisdom. While significant research still needs to be done in understanding the development of a 'wise mind', we have found that mindfulness meditation may be a useful tool to help leaders develop greater wisdom in their practice; that is to be more reflective, be more willing to tolerate ambiguity, value diversity, retain greater emotional control during periods of stress and be more relational (pro-social) in their behaviours.

In our experience of designing leadership workshops for leaders in the oil and gas sector, we have used reflection exercises to help leaders consider the nature and their approach to wisdom; asking what makes a 'wise leader' and how they may go about becoming 'wiser'. These reflective exercises have led to interesting discussions and fresh insights for participants.

To encourage our participants to go further, we have offered the opportunity of take-away self-reflection (meditation) exercises. We have summarized three practices below which could be used within a leadership development programme, and which might contribute towards wisdom through a mindful-informed approach to learning (Table 2).

Table 2: Three Practices for Wisdom

\begin{tabular}{|l|l|}
\hline $\begin{array}{l}\text { Stepping out } \\
\text { of the thought } \\
\text { stream }\end{array}$ & $\begin{array}{l}\text { While leaders are 'always on', they rarely deeply reflect on the task, } \\
\text { process or themselves. By returning attention repeatedly to } \\
\text { moment-to-moment sensations, leaders can gain a perspective on } \\
\text { their thought processes, their emotions and how these connect } \\
\text { with events (triggers) and their behaviour (responses), as well as } \\
\text { how the responses in turn send a ripple through the wider } \\
\text { organization. }\end{array}$ \\
\hline $\begin{array}{l}\text { Being with } \\
\text { discomfort }\end{array}$ & $\begin{array}{l}\text { As individuals we can often push away from discomfort or negative } \\
\text { sensations. The capacity to step back and resist the urge for } \\
\text { immediate personal comfort is a key skill for those in positions of } \\
\text { power. The ability to resist is only possible if we can understand the } \\
\text { instincts that drive our behaviour towards pleasure and away from } \\
\text { pain. Learning to sit with, and bear, a discomfort, such as the } \\
\text { repeated buzz of an insect, can to create the ability in oneself to sit } \\
\text { with negative sensations, allows leaders to ride the ups and downs }\end{array}$ \\
\hline
\end{tabular}

Passmore, J. (2019). Mindfulness in organizations (Part 2): A practitioners' guide to applying mindfulness based approaches in leadership development, workplace wellbeing and coaching. Industrial and Commercial Training. DOI: 10.1108/ICT-072018-0064 


\begin{tabular}{|l|l|}
\hline & $\begin{array}{l}\text { of misfortune that beset all organizations and individuals during a } \\
\text { career or a business life-cycle. }\end{array}$ \\
\hline Embracing & $\begin{array}{l}\text { Leaders can sometimes find themselves moving between two } \\
\text { opposite polarities. One moment, week, month 'I am great'. The } \\
\text { next week, month, quarter; I am stupid'. Or 'I am strong'. 'I am } \\
\text { weak'. Mindfulness practice allows leaders to tolerate apparently } \\
\text { opposing views, accepting that both can have truth depending on } \\
\text { the situation, the observer or our personal emotional state. Truth is } \\
\text { not an absolute; it is mediated by factors such as time, specific } \\
\text { event and personal construct. }\end{array}$ \\
\hline
\end{tabular}

The common thread that links these is the importance of encouraging leaders to be mindful. By this we mean actively and regularly observe ones own thinking from the outside; developing an understanding of how we are in the multiple situations, interactions and states that we enjoy (or endure) during a working day or week. Secondly, reflecting in a non-goal oriented and non-judgmental way: being, experiencing, accepting, while continuing to observe.

In each case the use of a reflective stance can enhance the process. We commonly use eight questions (Table 3 ) to enable a greater understanding by the leader to their personal response and the learning that can emerge from any situation.

\section{Table 3: The Henley Eight}
1. What have you observed?
2. How did you respond? (think about your behaviour, your emotions and your thoughts?)
3. What does that tell you about you as a person (your beliefs and assumptions)
4. What does that tell you about you as a leader (your beliefs and assumptions about others)
5. What strengths (advantages) do these offer?
6. What pitfalls (disadvantages) do these offer?
7. How might you respond differently next time?
8. What did you learn about yourself, the person and the situation?

For example in a project with an organizational management team experiencing high levels of conflict resulting from stress and fatigue, mindfulness based intervention helped the team to reflect on how they worked together to achieve positive outcomes. The team was taught how to reflect on their emotional states, by using a four-minute body scan. Following this the team were invited to open the envelopes containing their task and start work. The task involved a construction of miniature shopping trolleys against the clock. The task demanded effective communication, task focus and managing time constraints. The task was set to last 20 minutes. Five minutes into the task, the sound of buzzing flies was introduced. The management

Passmore, J. (2019). Mindfulness in organizations (Part 2): A practitioners' guide to applying mindfulness based approaches in leadership development, workplace wellbeing and coaching. Industrial and Commercial Training. DOI: 10.1108/ICT-072018-0064 
team members were asked to do their best to avoid this distraction and to remain focused on the task. In a facilitated reflective exercise after the task, the team members talked about how they saw parallels between the task and their work: irritating but low priority distractions often conflicted with other demands, leading to stress and team conflict. Using mindfulness techniques was a way to manage distractions, stress, fatigue and conflict.

This example is just one-way leadership teams can be exposed to these ideas. The learning value however comes from the personal reflection and plenary discussion that follows such an exercise. However, as with most organizational initiative interventions what was missing was a robust evaluation. How did the intervention create a different perspective that lead to sustainable change? While qualitative feedback in terms of programme evaluations provides some evidence of the benefits, designing an intervention with the evaluation from the start, and including quantitative data, may provide us with clearer evidence of the organizational value, such as reduced accidents on a vessel where mindfulness has been taught managers and shift supervisors

\section{Mindfulness wellbeing programs}

The second area where mindfulness can be deployed is within an organizational wellbeing program. Such programmes have grown significantly in popularity. The US Army has introduced a mindfulness based fitness program (Jha, et al., 2010), while others including Google (Kelly, 2012) and General Mills (Gelles, 2012), have started to run programmes as part of the learning and development strategy.

As highlighted above, in the health-based research, one of the most popular formats for developing mindfulness is the eight-week mindfulness programme. However, for most organizations an eight-week programme is too long and too intensive. As a result organizations have tended to favour two shorter alternatives when introducing mindfulness.

One option is offering mindfulness as part of a stress management programme, possibly as short as a single day. A second approach is dividing the intervention into a series of short or half-day interventions delivered once a month over several months. Finally, and one which works well if there is an internal resource to deliver the programme, is to offer mindfulness as a weekly drop-in lunchtime session. Individuals are encouraged to use the learning and apply these in their daily regime.

Such bite-size approaches offer organizations practical ways to introduce mindfulness to workers, without the programme taking over or negatively effecting the day job. Our experience has been of a phased teaching, with a different technique being taught each week in the 30 or 60 -minute lunchtime session. Over the programme individuals build a range of tools to use and more importantly through regular practice at these lunchtime sessions are more likely to add the

Passmore, J. (2019). Mindfulness in organizations (Part 2): A practitioners' guide to applying mindfulness based approaches in leadership development, workplace wellbeing and coaching. Industrial and Commercial Training. DOI: 10.1108/ICT-072018-0064 
practice to their own schedules than a simple one-day course. Typical practices include IED, Stop and Being the Observer (Passmore and Amit, 2017).

Evaluation of such programmes can certainly be undertaken, with the impact of mindfulness training on organizational factors from absenteeism to turnover, or team performance (sales figures) to external customer satisfaction.

Table 4: Three Practices for Mindfulness

\begin{tabular}{|l|l|}
\hline $\begin{array}{l}\text { Identifying } \\
\text { environmental } \\
\text { distractions } \\
\text { (IED) }\end{array}$ & $\begin{array}{l}\text { This exercise is a suggestion on how we can become clearer about } \\
\text { what is disturbing our attention and how this impacts on our level } \\
\text { of concentration and our productivity / personal relationships }\end{array}$ \\
\hline STOP & $\begin{array}{l}\text { This exercise is a suggestion to help us become more proactive by } \\
\text { stopping and choosing mindfully how we want to continue with our } \\
\text { day. It's something we can do that does not require much time }\end{array}$ \\
\hline $\begin{array}{l}\text { Being the } \\
\text { observer }\end{array}$ & $\begin{array}{l}\text { Rumination is a common human trait. It can happen especially } \\
\text { when the client is upset about something that has happened or a } \\
\text { conversation that went wrong. When the client over identifies with } \\
\text { their thinking they can become anxious and stressed. The exercise } \\
\text { is aimed to help clients to acknowledge that they are not their } \\
\text { thoughts, and their thoughts are not the truth }\end{array}$ \\
\hline
\end{tabular}

\section{Mindfulness coaching}

Along with the growth of mindfulness practice in consulting assignments, mindfulness has also impacted coaching practice. A range of writers including Spence (2008), Hall (2013), Passmore \& Marianetti (Passmore \& Marianetti, 2007; Marianetti \& Passmore, 2009) and Chaskalson \& McMordie (2017) have written on the topic offering tools, techniques and mindfulness interventions coaches can adopt and use with their clients, while coach training providers are now offering specialist coach training courses on mindfulness coaching.

It has been argued that mindfulness practice delivered through coaching can offer similar benefits to those gained through training, with mindfulness benefiting the coach, the individual client and the wider coach-client relationship. These benefits may arise in four ways; preparing for coaching, maintaining focus in coaching, managing emotions in coaching and teaching clients mindfulness.

Firstly in helping the coach to prepare for coaching. One challenge most individuals face, not just the coach is the challenge of the wandering mind. The coach may be moving from one organizational client offices to another, battling the public transport system or city roads, or simply moving from one conference call to the next. In these situations the wandering mind can lead to the mind gravitate back to 
the previous meeting, or drifting off to consider the next call. Mindfulness offers a practical way of putting such demands aside, and focusing on the here and now and the individual client who is sitting in front of us.

It can also be useful for the coach in helping maintaining focus in an individual session. With coaching sessions of an hour to two, the wandering mind can draw the coach away from full attention in the session to consider what may be happening later in the day or the next day.

A third challenge faced by the coach is the relationship, specifically the emotions created from client engagement. The coach may be drawn to the coachee; physically or intellectually: 'Inappropriate relationships with clients' remains the largest single reason why therapists and psychologists are removed from their professional registers, and given the limited number of complaints in counselling its not surprising there is little reported evidence of this in coaching, we suspect that such practices are likely to be common in coaching, as an intimate 1-1 relationship. More common is the issue of the coach being drawn into the dialogue as an ally, for example supporting the 'victim-client' against the 'aggressive organization', who just happens to be paying for the coaching sessions. Mindfulness provides a resource to be more aware of these natural human emotional responses, of attraction and collusion, and from the coach to be able to better able to identity and to manage their response.

Finally, as with training the coach may wish to share with their individual clients some of the science of mindfulness, or tools to use between sessions. Given some of the scepticism about meditation and mindfulness, I have found in my own practice it can sometimes help to present the ideas as techniques to aid concentration and focus, rather than under the label 'Mindfulness'. This change in language in some organizations makes the use of these techniques easy to accept and apply. However, for others who may be more accepting or have established religious practices, mindfulness can fit comfortably into these practices or established beliefs. What is important is for the coach to be flexible and to be able to adapt to meet the needs of individual clients and what serves their interests, as opposed to having a formula or script to follow which they apply to all.

But how can these elements be introduced to a client during coaching? One common approach I use, both for myself as a coach, and teach to some clients, is to introduce a four-minute mindful body scan before we start the coaching process. I have found this helpful in my own coaching practice. I spend four minutes while in the client's lobby checking out how I feel. A summary of my mental script is contained in Table 5.

As with the other interventions measuring the impact of mindfulness coaching over cognitive behavioural coaching or solution focused is difficult. There are questions of client variations, from personality to readiness, as well as organisational and coach factors. The best that might be achieved are measures of mindfulness on

Passmore, J. (2019). Mindfulness in organizations (Part 2): A practitioners' guide to applying mindfulness based approaches in leadership development, workplace wellbeing and coaching. Industrial and Commercial Training. DOI: 10.1108/ICT-072018-0064 
concentration, decision-making and relational factors. What is clear is that more research into the effects of mindful based coaching would be welcome.

\section{Table 3: The Lobby Body Scan}

Step 1: Finds somewhere comfortable to sit, and create a posture of erectness and dignity.

Step 2: Start to observe the breath; the in-breath and the out breath. Follow this for 8 or 9 cycles of slowly breathing in and out. Filling the lungs full, and slowing exhaling, before starting the cycle again.

Step 3: Start to be aware of what's going on in the body; any pains, tensions or sensations. Be open to these sensations, not judging them or seeking to explain them, but simply being aware of their existence.

Step 4: Direct the breath to any areas of tension or stress, and allow the breath to hold, caress and surround any uncomfortable sensations, allowing these sensations to dissolve or subside. Taking each place of tension or stress turn, and directing 8 or 9 breathes into each place, or as many as feels appropriate, until each subdues.

Step 5: Start to broaden the breath and become aware of the sensation of the whole body, sitting erect and dignified in the chair.

Step 6: Take that closing sensation into the next part of the day.

\section{Evaluation}

As discussed above, the evaluation of organizational interventions is more difficult than in many other contexts such as health. Many organizations relying on low cost and easy to execute evaluation methods, such as participant evaluation, while leaving quantitative measures with pre and post questionnaires to academics. Writers have however noted the multiple levels that evaluation can usefully occur (Kirkpatrick, 1979; Dessinger, \& Moseley, 2006; Warr et al., 1970; Passmore \& Veliz, $M, 2012$ ), but the application of more structured and quantitative measures is rare. A result of HR practitioners and managers lacking the time and skill, while academics often lack access to organizations at a senior level to enable evaluation to become an integrated part of any intervention from the design stage.

These experiences signal the need for stronger collaborations between practitioners, seeking to evaluate and quantify the impact of new interventions, and academics, with the skills and resources to undertake robust evaluations.

Passmore, J. (2019). Mindfulness in organizations (Part 2): A practitioners' guide to applying mindfulness based approaches in leadership development, workplace wellbeing and coaching. Industrial and Commercial Training. DOI: 10.1108/ICT-07- 
One evaluation option is the use of a pre-validated questionnaire, such as a psychometric questionnaire, or the use of a 360 competence frameworks. By measuring before and after the programme, and comparing the results with a control group, the impact of the programme can be more clearly established.

A second is the use of data using a within participant design to evaluate the impact of a programme over time on individual factors such as absenteeism, assuming that multiple interventions are not implemented simultaneously. These impacts at an individual level, such as a reduction in employee absenteeism from an average of 1.5 days per month to 1.2 days per month, has a net financial benefit which can be calculated and shared with the board.

A third is to look at over all performance, for example in the retail sector, implementing a series of changes in one store, region or vessel and comparing it with a similar store, region or vessel. What impact does this have on sales, contracts won or accident rates. Once again keeping contaminating factors to a minimum, allows a comparison which may provide a numerical measure of the benefits of mindfulness based interventions.

What however is key, and is the second missing step in much organization research, is to share the results through a published paper. Many organisations, from personal experience, are reluctant to do allow their data or name to appear, seeking to control all aspects of their public image. But in the same way that health studies mask the identities or hospitals and patients, organisations could achieve the same outcomes. What is required is a mindset about the value of sharing knowledge for wider society gain.

\section{Words of caution}

The number of studies in workplace settings using comparing mindfulness with a comparable intervention remains small. We are some way from understanding the benefits of mindfulness for organizations. While there remains considerable discussion in organizations about the value of mindfulness, and the proliferation of mindfulness books from 'mindfulness colouring' to 'mindfulness at work', few offer practical steps which consultants and trainers can take to integrate mindfulinformed interventions into existing organizational development.

At a process level writers have argued that as yet we do not fully understand the active ingredients within mindfulness practices and that greater caution is needed (Allen, et al., 2015). The criticism of mindfulness at work extends beyond process to conceptual concern about its use and misuse. Purser and Loy (2013) have criticized the growing trend of what they call 'McMindfulness', whereby soundly designed health based programmes such as the eight week MBSR are reduced to short bitesize interventions to fit organizational demands, such as lunchtime sessions. They argue that this leads to a transformation of mindfulness in to little more than a "... 
banal, therapeutic, self-help technique..." and removes the spirit which is at the very heart of the approach. The populations however from health settings to organizations are very different, and short bite size interventions, delivered over a 6 or 8 week period may still offer benefit to employees.

Carette and King (2005) offer an alternative argument. That the 'McMindfulness' approach results in a transfiguration from mystical activity to ordinary everyday practice. The danger they suggest is that mindfulness, and other faith practices, when applied as organizational interventions could be seen more as a tool to manage and manipulate disgruntled workers than to genuinely improve wellbeing or to transform lives. Such a response is laden with values about the nature of work and organizations.

Arthington's criticisms however are more fundamental. Adopting a Foucauldian perspective, Arthington argued: "mindfulness reinforces neoliberal ideology by promoting the concept of the responsible and autonomous individual who dedicates themselves to a lifelong project of self-improvement and self-discipline" (Arthington, 2016, p87).

\section{Future directions for research and practice}

In returning to the three areas of leadership wisdom wellbeing, and coaching research collaborations between organizations and consultants could begin to build evidence. We might suggest three avenues for future research collaborations. Firstly, in leadership development, a study that examined the impact of a mindfulness leadership on the development of leaders effectiveness, as rated by the team, through 360 evaluations would be a worthwhile study to undertake, and provide evidence to support the value claims being made of mindful leaders.

In wellbeing interventions, while using measures of positive and negative affect, such as PANAS (Positive and Negative Affect Scale) are helpful, the real impact for organizations is on absenteeism and turnover. As we have noted above, such a study would offer clear financial benefits that can be quantified from a reduction in these employee measures.

Finally, in coaching, the impact of mindful informed coaching on a manager rated team performance, compared with a team who were receiving tradition goal focused coaching would be a useful study to conduct.

\section{Conclusion}

In spite of these words of caution, mindfulness appears to be the current flavor of choice for organizations seeking novel and innovative interventions. Our experiencing of integrating mindfulness concepts into existing development practices has received positive responses at an experiential level, but for 
mindfulness to demonstrate its true value, practitioners and academics need to collaborate and design robust evaluations that allow the science to catch up with the claims of practitioners.

\section{References}

Arthington, P. (2016). Mindfulness: A critical perspective. Community Psychology in Global Perspective, 2(1), 87-104.

Baltes, P. B., \& Staudinger, U. (2009). Wisdom: A Meta-heuristic (Pragmatic) to Orchestrate Mind and Virtue Toward Excellence. American Psychologist, 55(1), $122-$ 136. DOI:10.1037//0003-066X.55.1.122.

Carrette, J., \& King, R. (2005) Selling Spirituality: The Silent Takeover of Religion. New York: Routledge.

Chaskalson, M. (2011). The Mindful Workplace: Developing resilient individuals and resonant organizations with MBSR. Chichester: Wiley.

Chaskalson, M \& McMordie, M. (2017). Mindfulness for Coaching. Hove:

Routledge

Cropley, M., \& Purvis, L. J. (2003). Job strain and rumination about work issues during leisure time: A diary study. European Journal of Work and Organizational Psychology, 12, 195-207. DOI: 10.1080/13594320344000093

Dessinger, J.C. \& Moseley, J.L. (2006). The full scoop on full-scope evaluation. In J.A. Pershing (Ed.), Handbook of Human Performance Technology: Principles, practices, potential, (pp.312- 330). San Francisco: Pfeiffer.

Gelles, D. (2012). Mindful work: How meditation is changing business from the inside out. New York, NY: Houghton Mifflin Harcourt.

Hall, L. (2013). Mindful Coaching: How Mindfulness can transform coaching practice. London: Kogan Page.

Hyland, P., Lee, A., \& Mills, M. (2015). Mindfulness at Work: A New Approach to Improving Individual and Organizational Performance. Industrial \& Organizational Psychology: Perspective on Science and Practice, 8(4), 576-602.

Jha, A. P., Stanley, E. A., Kiyonaga, A., Wong, L., \& Gelfand, L. (2010). Examining the protective effects of mindfulness training on working memory capacity and affective experience. Emotion, 10, 54-64.

Passmore, J. (2019). Mindfulness in organizations (Part 2): A practitioners' guide to applying mindfulness based approaches in leadership development, workplace wellbeing and coaching. Industrial and Commercial Training. DOI: 10.1108/ICT-072018-0064 
Kabat-Zinn, J. (1994). Full Catastrophe Living: How to cope with stress, pain and illness using mindfulness meditations. London: Piatkus.

Kelly, C. (2012, April 28). O.K., Google, Take a Deep Breath. New York Times.

Kirkpatrick,D. (1979).Techniques for evaluating training programs. Training and Development Journal, 78-92.

Lutz, A., Jha, A. P., Dunne, J. D., \& Saron, C. D. (2015). Investigating the phenomenological matrix of mindfulness-related practice from a neurocognitive perspective. American Psychologist, 70 (7), 632-658.

Marianetti, O., \& Passmore, J. (2009). Mindfulness at work: paying attention to enhance wellbeing and performance. In A. Lindley (ed.) Oxford Handbook of Positive Psychology and Work (pp189-200). Oxford: Oxford University Press.

Meeks, T. W., Dilip V., \& Jeste, M. (2009). Neurobiology of Wisdom: A Literature Overview. Archive of General Psychiatry, 66(4), 355-365. DOI:

10.1001/archgenpsychiatry.2009.8.

Passmore, J. (2007). Integrative coaching: a model for executive coaching'. Consulting Psychology Journal: Practice and Research, American Psychology Association, 59(1), 68-78.

Passmore, J. (2019). Mindfulness at organizations (Part 1): A critical literature review. Industrial \& Commercial Training. DOI: 10.1108/ICT-07-2018-0063

Passmore, J. \& Amit, S. (2017). Mindfulness at work: The practice and science of mindfulness for leaders, coaches and facilitators. New York: Nova Science

Passmore, J., \& Marianetti, O. (2007). The role of mindfulness in coaching. The Coaching Psychologist, 3(3), 131-138.

Passmore, J. \& Veliz, M. (2012) SOAP-M: A training evaluation model for HR. Industrial and Commercial Training, 44(6), 315-325. DOI.org/10.1108/00197851211254743

Purser, R., \& Loy, D., (2013, July 1). Beyond McMindfulness. The Huffington Post. Retrieved on 1 July 2018 from http://www.huffingtonpost.com/ron-purser/beyondmcmindfulness b 3519289.html

Rogers, C. (1961). On becoming a person: A therapist's view of psychotherapy. London: Constable.

Passmore, J. (2019). Mindfulness in organizations (Part 2): A practitioners' guide to applying mindfulness based approaches in leadership development, workplace wellbeing and coaching. Industrial and Commercial Training. DOI: 10.1108/ICT-072018-0064 
Spence, G. (2008). New directions in evidence-based coaching: investigations into the impact of mindfulness training goal attainment and wellbeing. Saarbrucken, Germany: VDM.

Warr P, Bird M, Rackham N. (1970). Evaluation of management training: A practical framework, with cases, for evaluating training needs and results. London: Gower Press. 